\title{
Monotonicity of drive effects in the instrumental conditioning of attitudes
}

\author{
ROBERT FRANK WEISS, VICKIE L. WENNINGER, and SUSAN SICLARI BALLING \\ University of Oklahoma, Norman, Oklahoma 73019
}

and

\author{
FRANKLIN G. MILLER \\ Department of Consumer Sciences, Purdue University, West Lafayette, Indiana 47907
}

\begin{abstract}
Instrumentally conditioned attitude strength was a monotonically increasing function of drive. A speed (100/latency) measure of conditioned attitude strength was employed. Speeds of the three drive groups were significantly different in the predicted rank order: low, medium, and high $(p<.001)$. Results were predicted from a theory of persuasive communication that is based on systematic analogies with conditioning and selective learning.
\end{abstract}

Modern neo-Hullian theories of instrumental conditioning commonly assume that response speed is an increasing function of drive (D) (e.g., Capaldi, in press; McHose \& Moore, 1976; Miller, 1971; Spence, 1956). Experimental tests of a theory of persuasive communication that is quite closely modeled upon instrumental conditioning have shown that speed (100/latency) of agreement is an increasing function of drive (e.g., Weiss, 1968). Our research has previously been limited to two levels of drive, and the purpose of the present experiment was to determine whether these effects are monotonic.

\section{METHOD}

There were three levels of drive, represented by low, medium, and high scores on the Manifest Anxiety Scale (e.g., Spence \& Spence, 1966). Experimental studies of drive employing this scale commonly utilize relatively extreme high and low levels of anxiety (e.g., the top and bottom quartiles), much as we have done in our previous research. In the hope of obtaining a clear differentiation in results, we sharpened the differentiation in anxiety scores, selecting from our subject population the highest one-sixth, the lowest one-sixth, and one-sixth grouped closely around the median. The statistical test that we planned to use is admirably sensitive to such differentiation (Nelson \& Toothaker, 1975). Anxiety was measured in the laboratory immediately prior to persuasion. The subjects were 54 undergraduates, 18 in each of the three anxiety groups.

Under the impression that he was participating in a study of "speech patterns and decision making," each experimental subject read three persuasive communications and three buffers into a tape recorder. There were two reading sessions within the 30-min experimental period, each followed immediately by attitude measurement. The first reading session covered two persuasive communications and two buffers, and the second session covered one persuasive communication and one buffer.

The persuasive communications were structured in such a

Reprints may be obtained from R. F. Weiss, Department of Psychology, University of Oklahoma, Norman, Oklahoma 73019. way as to be theoretically analogous to discrete-trials instrumental conditioning, as it might be conducted in a straight alley (Weiss, 1968). Attitude change researchers usually find it convenient to reverse opinions already strongly held by the subjects, a procedure that more nearly resembles habit reversal in selective learning than it does the strengthening of a single initially weak response in conditioning. In order to study "conditioning," rather than "habit reversal," the persuasive communicaions were directed at fictitious opinion topics, on which $96 \%-98 \%$ of a sample of 100 similar undergraduates had no initial opinion.

The attitude measuring apparatus assessed each subject's speed of agreement with the opinion after the subject had been exposed to persuasive communication. A statement of the opinion (preceeded by 11-13 buffers) was projected on a screen, and the subject signified his agreement (if he agreed) by moving a lever toward the opinion. When an opinion was projected on the screen, an electric timer automatically began to measure latency of agreement to $.01 \mathrm{sec}$. When the lever was moved .25 in., a photobeam silently stopped the timer (speed $=$ 100/latency). The timing equipment was not visible to the subjects, who did not know that they were being timed. If a subject did not respond within $40 \mathrm{sec}$, his speed of agreement with that opinion was considered to be zero. Subjects who did not agree did not move the lever. The mean of the three speed scores was computed for each subject.

Theoretically, speed of agreement should be a monotonically increasing function of drive, with speeds showing the same rank order as the three drive groups: low, medium, high.

\section{RESULTS}

Speed of agreement was a monotonically increasing function of drive. The three drive groups clearly show the predicted rank order of speed: low, medium, high, with the respective speeds of $9.7,13.2$, and 16.7. The Jonckheere test (Jonckheere, 1954; Kirk, 1968, Nelson \& Toothaker, 1975) is an elegant k-sample generalization of the Mann-Whitney test, ideally suited for testing the significance of the rank ordering of groups and the differences between them in a single operation. A Jonckheere test indicated that the speeds of the three 
groups were significantly different in the predicted rank order: low, medium, and high $(\mathrm{z}=3.81, \mathrm{p}<.001)$.

\section{DISCUSSION}

The research reported here derives from a theory of attitude learning (Weiss, 1968) that is based on systematic analogies with learning research and neo-Hullian learning theory. Results include, for example, analogs of acquisition trials effects, magnitude of reinforcement effects, and an elegant 5-point delay of reinforcement gradient. Part of the charm of these results resides in the fact that persuasive communications are not straight alleys and people are not rats. Yet these results were predicted by theoretical analogies with the behavior of white rats in straight alleys. So, too, is the case for the present study of drive effects, in which we have taken some care to differentiate between our "conditioning" procedure and persuasion procedures that more nearly resemble habit reversal in selective learning. Doubtless, attitude change through persuasive communication is in some sense complex, and surely we deal only with analogs of the boundary conditions of conditioning and selective learning. Yet we report here results that are analogous to drive effects in conditioning, just as we have previously reported the predictably different effects of drive in a persuasion analog of selective learning.

\section{REFERENCES}

CAPAldi, E. J. Reinforcement level: An expectancy-associative approach to relative reinforcement and nonreinforcement effects. In J. W. Baerwaldt \& G. McCain (Eds.), Recent developments in learning theory. Stamford, Conn: Greylock, in press.

Jonckнeеre, A. R. A distribution-free k-sample test against ordered alternatives. Biometrika, 1954, 41, 133-145.

KIRK, R. E. Experimental design: Procedures for the behavioral sciences. Monterey, Calif: Brooks/Cole, 1968.

McHose, J. H., \& Moore, J. N. Expectancy, salience, and habit: A noncontextual interpretation of the effects of changes in the conditions of reinforcement on simple instrumental responses. Psychological Review, 1976, 83, 292-307.

Miller, N. E. Neal E. Miller: Selected papers. Chicago: Aldine, 1971.

Nelson, P. L., \& Toothaker, L. E. An empirical study of Jonckheere's nonparametric test of ordered alternatives. British Journal of Mathematical and Statistical Psychology, 1975, 28, 167-176.

Spence, J. T., \& SPence, K. W. The motivational components of anxiety: Drive and drive stimuli. In C. D. Spielberger (Ed.), Anxiety and behavior. New York: Academic Press, 1966.

SPENCE, K. W. Behavior theory and conditioning. New Haven, Conn: Yale University Press, 1956.

WEISS, R. F. An extension of Hullian learning theory to persuasive communication. In A. G. Greenwald, T. C. Brock, \& T. M. Ostrom (Eds.), Psychological foundations of attitudes. New York: Academic Press, 1968.

(Received for publication September 25, 1980.) 